\title{
ANALISIS ESTIMASI COST-VOLUME-PROFIT (CVP) DALAM HUBUNGANNYA DENGAN PERENCANAAN LABA PADA HOTEL TLOGO MAS SARANGAN
}

\author{
Satrijo Budiwibowo \\ Pendidikan Akuntansi IKIP PGRI Madiun
}

\begin{abstract}
This research aims to analyze the estimated Cost-Volume-Profit (CVP) in association with the Profit Planning at Tlogo Mas Hotel Sarangan. Analytical techniques used in this study were: (1) Classify all costs incurred in the variable costs (variable costs) and fixed costs (fixed cost). (2) Method of least squares analysis. (3) Analysis of the breakeven point (Break Event Point / BEP). The results showed that Tlogo Mas Hotel Sarangan determine the profits of $10 \%$ of total sales. It is seen from the fluctuations experienced profit growth each year from 2009 to 2011.
\end{abstract}

Key words: Cost-Volume-Profit, Profit Planning, Method of least squares analysis and Break Event Point Analysis.

\begin{abstract}
ABSTRAK
Penelitian ini bertujuan untuk menganalisis estimasi Cost-Volume-Profit (CVP) dalam Hubungannya dengan Perencanaan Laba Pada Hotel Tlogo Mas Sarangan. Teknik analisis yang digunakan dalam penelitian ini adalah: (1) Mengklasifikasikan semua biaya-biaya yang dikeluarkan ke dalam biaya variabel (variable cost) dan biaya tetap (fixed cost). (2) Metode analisis kuadrat terkecil. (3) Analisis titik impas (Break Event Point/BEP). Hasil penelitian menunjukkan bahwa Hotel Tlogo Mas Sarangan menetapkan laba sebesar $10 \%$ dari total penjualan. Hal ini terlihat dari fluktuasi kenaikan laba yang dialami tiap tahunnya mulai dari tahun 2009 hingga 2011.
\end{abstract}

Kata Kunci: Cost-Volume-Profit, Perencanaan Laba, Metode analisis kuadrat terkecil dan Analisis titik impas.

\section{PENDAHULUAN}

Pada era globalisasi ini dunia perekonomian mengalami krisis, tantangan dan rintangan yang cukup mengkhawatirkan dan dirasakan oleh beberapa negara. Hal ini membuat persaingan bisnis, khususnya disektor barang dan jasa semakin sulit, terutama pada bisnis jasa perhotelan. Sejalan dengan kebijakan pemerintah untuk mendorong pertumbuhan sektor riil, maka persaingan antar perusahaan khususnya yang sejenis semakin meningkat. Untuk menjaga kesinambungan hidup perusahaan dalam menghadapi persaingan yang ketat diperlukan penanganan dan pengelolaan yang baik. Penanganan dan pengelolaan yang baik tersebut hanya dapat dilakukan oleh manajemen yang baik pula. Pihak manajemen selain dituntut untuk dapat mengkoordinasikan seluruh sumber daya yang dimiliki perusahaan secara efektif dan efisien, juga dituntut untuk membuat keputusan manajerial guna menunjang tercapainya tujuan perusahaan 
secara efektif dan efisien. Manajer harus dapat berpikir kritis dalam mengambil setiap keputusan agar dapat mengikuti perkembangan dan perubahan yang terjadi.. Kemampuan berfikir inilah yang dapat membuat satuan unit bisnis untuk dapat bertahan dalam situasi persaingan yang cukup ketat, baik persaingan kompetitif (Competitve advantage) maupun persaingan komparative (Comparative advantage)

Manajer memerlukan suatu pedoman berupa perencanaan yang memuat langkah-langkah yang akan dan harus di tempuh satuan unit bisnis dalam mencapai tujuanya. Perencanaan dapat pula berupa alat ukur dan evaluasi atas hasil sesungguhnya yang telah dilaksanakan sebagai bentuk realisasi dari sebuah perencanaan. Apabila hasil sesungguhnya tidak sesuai dengan apa yang di rencanakan, maka manajer harus mengevaluasi ketidaksesuaian tersebut dan mengambil tindakan-tindakan yang diperlukan untuk mengatasinya. Perencanaan juga merupakan alat untuk pengendalian terhadap kegiatan-kegiatan yang akan di lakukan. Dengan demikian, perencanaan memegang peranan sangat penting dalam menunjang kegiatan-kegiatan satuan unit bisnis.

Perencanaan yang baik dapat membantu dalam penaksiran tingkat laba yang akan didapat satuan unit bisnis, sehingga laba yang diperoleh bisa optimal. Untuk mencapai laba yang optimal (dalam perencanaan laba dan realisasi), manajer-manajer dapat menggunakan langkah-langkah sebagai berikut :

1. Menekan biaya operasional serendah mungkin (melakukan efisiensi) dengan mempertahankan tingkat harga dan volume penjualan yang ada.

2. Menentukan tingkat harga jual sedemikian rupa sesuai dengan laba yang dikehendaki.

3. Meningkatkan volume penjualan sebesar mungkin

Perlu diingat bahwa ketiga langkah tersebut tidak dapat dilakukan secara terpisah sebab ketiganya mempunyai hubungan yang saling berkaitan dalam mengambil suatu keputusan dan perumusan suatu kebijakan satuan unit bisnis masa yang akan mendatang.

Salah satu tujuan dari suatu satuan unit bisnis adalah untuk memperoleh laba yang optimal sehingga salah satu perencanaan yang dibuat pihak manajemen adalah perencanaan laba. Perencanaan laba tersebut memuat langkah-langkah yang harus ditempuh satuan unit bisnis untuk mencapai besarnya target laba yang diinginkan. Karena laba merupakan selisih antara pendapatan yang diterima (hasil penjualan) dengan biaya yang dikeluarkan. Dengan demikian perencanaan laba dipengaruhi oleh perencanaan penjualan (estimasi penjual) dan perencanaan biaya (estimasi biaya). Untuk membuat perencanaan laba yang baik, maka diperlukan alat bantu berupa analisis biaya-volume-laba (cost-volume-profit/CVP).

Analisis biaya-volume-laba (cost-volume-profit/CVP) yang penting adalah analisis titik impas (Break Event Point Analysis) analisis Break Event Point adalah teknik analisis untuk mengetahui penjualan minimum agar satuan unit bisnis tidak menderita rugi, tetapi juga belum memperoleh laba (dengan kata lain labanya sama dengan nol). Dengan melakukan analisis Break Event Point, manajemen akan memperoleh informasi tingkat penjualan minimum yang harus dicapai, agar tidak mengalami kerugian. Dari analisis tersebut, juga dapat diketahui sampai seberapa jauh volume penjualan yang direncanakan boleh turun, agar satuan unit bisnis tidak mengalami kerugiaan. Oleh karena itu, analisis break event point merupakan alat yang efektif dalam menyajikan informasi manajemen untuk keperluan perencanaan laba sehingga manajer dapat memilih berbagai usulan kegiatan yang akan memberikan kontribusi terhadap pencapaian laba dimasa yang akan datang. 
Analisis Cost-volume-profit dapat juga digunakan pada industri jasa, misalnya industri jasa perhotelan. Dalam industri perhotelan, satuan unit bisnis dituntut bagaimana menghasilkan dan memasarkan berbagai jasa yang terdapat pada hotel tersebut bagi konsumen yang membutuhkanya. Pendapatan jasa perhotelan dipengaruhi oleh berbagai faktor, salah satunya adalah tingkat kepadatan hunian.

Hotel Tlogo Mas adalah hotel yang terletak di daerah wisata Sarangan yang cukup dikenal dikawasan Jawa Timur. Bertitik tolak dari latar belakang yang telah diuraikan di atas,maka permasalahan pokok dalam penelitian ini adalah: "Bagaimana menganalisis estimasi Cost-Volume-Profit (CVP) dalam Hubungannya dengan Perencanaan Laba Pada Hotel Tlogo Mas Sarangan”.

\section{TELAAH LITERATUR}

Salah satu sasaran penting bagi organisasi yang berorientasi pada profit oriented adalah menghasilkan laba. Oleh karena itu jumlah laba yang dihasilkan dapat dipakai sebagai salah satu alat ukur efektivitas, karena laba adalah selisih antara pendapatan (yang merupakan ukuran keluaran) dan pengeluaran (yang merupakan ukuran masukan). Sedangkan menurut pendapat Harahap (2005:263) "Laba merupakan angka yang penting dalam laporan keuangan karena berbagai alasan antara lain: laba merupakan dasar dalam perhitungan pajak, pedoman dalam menentukan kebijakan investasi dan pengambilan keputusan, dasar dalam peramalan laba maupun kejadian ekonomi perusahaan lainnya di masa yang akan datang, dasar dalam perhitungan dan penilaian efisiensi dalam menjalankan perusahaan, serta sebagai dasar dalam penilaian prestasi atau kinerja perusahaan"

Dasar keberhasilan perencanaan adalah ketaatan dan kegairahan pelaksana terhadap perencanaan laba. Perencanaan laba bukan merupakan hal yang mudah, karena penerapannya harus didasarkan pada pertimbangan-pertimbangan keadaan intern maupun ekstern perusahaan baik yang langsung maupun tidak langsung mempengaruhi penetapan laba itu sendiri.

Menurut Machfoedz (2008: 23) perencanaan laba adalah "sebuah penentuan terhadap tindakan yang akan dilakukan oleh manajemen dalam jangka waktu tertentu yang berhubungan dengan target laba yang ingin dicapai perusahaan". Pendapat tersebut sejalan dengan pendapat Soepriyono (2002: 331) yang menyatakan bahwa Perencanaan laba (profit planning) adalah "perencanaan yang digambarkan secara kuantitatif dalam keuangan dan ukuran kuantitatif lainnya. Didalamnya juga ditentukan tujuan laba yang dicapai oleh perusahaan".

Dalam kaitannya dengan perencanaan laba, salah satu indikator yang tidak boleh dikesampingkan adalah faktor biaya. Biaya (cost) adalah kas atau setara kas yang dikorbankan (dibayarkan) untuk barang atau jasa yang diharapkan memberikan manfaat (pendapatan) pada saat ini atau mendatang bagi organisasi. Disebut setara kas (cash equivalent) karena sumber daya non kas dapat ditukarkan dengan barang atau jasa yang dikehendaki. Biaya yang akan memberikan manfaat (benefit) hanya pada periode berjalan / sekarang (current periode) biasanya dicatat sebagai beban (expense)

Menurut Hongren, Foster, dan Datar (2005:28), "Cost as a resource sacrificed or forgone to achieve a specific objective". Menurut pengertian ini, biaya yaitu sebagai sumberdaya yang dikorbankan atau dikeluarkan untuk mencapai tujuan tertentu. Sedangkan Mursyidi (2008: 7) menyatakan bahwa cost adalah suatu pengorbanan yang dapat mengurangi kas atau harta lainya untuk mencapai tujuan,baik yang dibebankan pada saat ini maupun pada saat yang akan datang. Sedangkan expense adalah biaya yang telah terjadi yang dikurangkan dari penghasilan atau dibebankan pada periode yang 
bersangkutan dimana pengorbanan terjadi.

Adapun pendapat beberapa ahli mengenai perbedaan antara biaya (cost) dengan beban (expense), Menurut Polimeni (1991:14) : "Cost is defined as the value of the sacrifice made to acquire goods or services, measured in dollars by the reduction of assets or incurrence of liabilities at the time the benefit are required. An expense is defined as cost that has given a benefit and is now expired. Unexpired cost that can give future benefits are clasified as assets. Expenses are matched against revenues to determine net income or loss for period".

Definisi di atas memberikan pemahaman yang jelas bahwa cost merupakan sejumlah nilai yang dikorbankan untuk memperoleh barang dan jasa, dimana pengorbanan tersebut diukur dengan berkurangnya harta atau bertambahnya kewajiban pada saat perolehan dalam satuan moneter (rupiah). Expense didefinisikan sebagai biaya yang telah memberikan manfaat dan ketika manfaat tersebut digunakan. Cost yang akan memberikan manfaat di masa yang akan datang dicatat sebagai aktiva (asset) dan dicantumkan dalam neraca, sedangkan cost yang telah memberikan manfaat dicatat sebagai expense dan dicantumkan dalam laporan laba rugi.

\section{Analisis Cost-Volume-Profit (CVP)}

"Analisis cost-volume-profit adalah salah satu dari beberapa alat yang sangat berguna bagi manajer dalam memberikan perintah. Alat ini membantu manajer untuk memahami hubungan timbal balik antara biaya, volume, dan laba".(Garrison; Noreen; 2006:322)

Adapun pengertian CVP menurut Blocher;Chen;Cokins;Lin (2009:387) : "Analisis cost-volume-profit merupakan metode untuk menganalisis bagaimana keputusan operasi dan keputusan pemasaran mempengaruhi laba bersih, berdasarkan pemahaman tentang hubungan antara biaya variabel, biaya tetap, harga jual per unit, dan tingkat output". Dari pengertian tersebut dapat disimpulkan bahwa analisis CVP dapat menjadi alat yang berharga untuk mengidentifikasi luas dan besarnya masalah ekonomi yang dihadapi perusahaan dan membantu menunjukkan secara tepat jawaban yang diperlukan. Analisis CVP juga dapat ditujukan pada banyak isu lainnya, seperti: jumlah unit yang harus dijual agar impas; dampak pengurangan biaya tetap pada titik impas; dan dampak peningkatan harga pada laba. Sebagai tambahan, analisis CVP memungkinkan manajer untuk melakukan analisis sensitivitas dengan menguji pengaruh berbagai tingkat harga atau biaya pada laba.

\section{Analisis Titik Impas (Break Event Point/BEP)}

Analisis biaya-volume-laba seringkali diartikan sebagai analisis titik impas. Hal ini sangat disayangkan karena analisis titik impas hanyalah satu elemen dalam analisis biaya-volume-laba, walaupun merupakan elemen yang penting.

Menurut Bustami (2006: 208) Analisis Break Even Point adalah : "Suatu cara atau teknik yang digunakan oleh seorang manajer perusahaan untuk mengetahui pada volume (jumlah) penjualan dan volume produksi berapakah suatu perusahaan yang bersangkutan tidak menderita kerugian dan tidak pula memperoleh laba".

Secara ringkas dikatakan oleh Blocher;Chen;Cokins;Lin (2009: 392) bahwa "Titik impas adalah titik ketika pendapatan sama dengan biaya total dan laba sama dengan nol". Disisi lain Bustami (2006: 208-209) mengemukakan bahwa: "analisis biaya, volume, dan laba maupun titik impas akan memberikan hasil yang memadai apabila asumsi berikut terpenuhi: 
1. Perilaku penerimaan dan pengeluaran dilukiskan dengan akurat dan bersifat linier sepanjang jangkauan (rentang) yang relevan.

2. Biaya dapat dipisah menjadi biaya tetap dan biaya variabel.

3. Efisiensi dan produktivitas tidak akan berabah.

4. Harga jual tidak akan mengalami perubahan.

5. Biaya-biaya tidak berubah.

6. Bauran penjualan tetap konstan.

7. Tidak ada perbedaan yang signifikan (nyata) antara persediaan awal dan persediaan akhir".

Hubungan biaya-volume-laba dapat digambarkan secara grafik dengan menyiapkan grafik biaya-volume-laba. Grafik biaya-volume-laba menekankan hubungan biaya-volume-laba pada berbagai tingkat aktivitas.

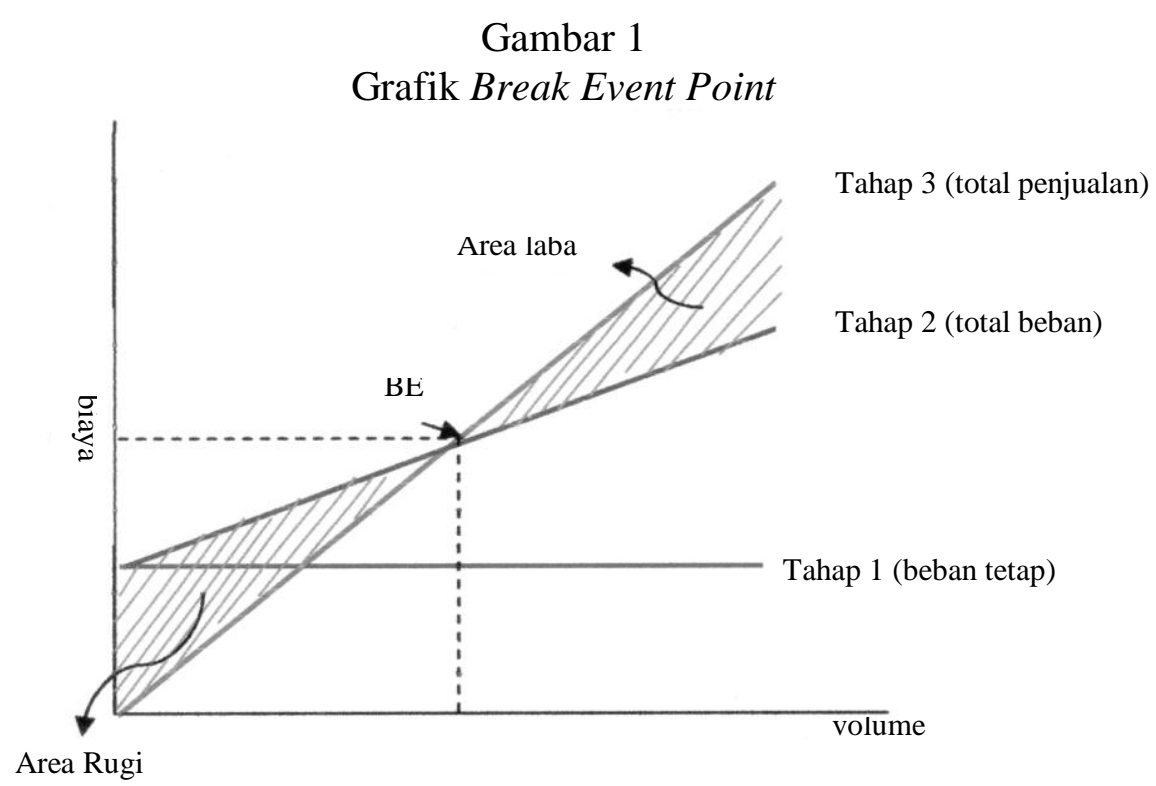

Pada grafik biaya-volume-laba (CVP), volume per unit digambarkan dalam sumbu horizontal dan nilai uang dalam sumbu vertikal.

\section{HIPOTESIS PENELITIAN}

Menurut Suharsimi Arikunto (2006:70) "Hipotesis adalah suatu jawaban yang bersifat sementara terhadap permasalahan penelitian,sampai terbukti melalui data yang terkumpul" Dalam penelitian ini hipotesisnya adalah ada hubungan tentang estimasi cost volume profit terhadap perencanaan laba pada Hotel Tlogo Mas, Sarangan.

\section{RANCANGAN PENELITIAN}

1. Metode Penelitian

Metode yang digunakan dalam penelitian ini adalah metode penelitian deskriptif korelasional dengan maksud untuk mengetahui hubungan antara variabel yang satu (X) dengan variabel yang lain (Y), sehingga dengan menggunakan metode penelitian ini, peneliti mengetahui ada tidaknya hubungan cost volume profit terhadap perencanaan laba. Disamping itu dilakukan estimasi melalui analisisi statistik regresi sederhana guna membantu menentukan besarnya perencanaan 
perkiraan biaya.

2. Desain Penelitian

Desain penelitian yang digunakan peneliti dalam penelitian ini adalah deskriptif korelasional yaitu penelitiian yang dilakukan untuk menjelaskan bagaimana satu variabel di hubungkan dengan variabel lain. Hubungan tersebut dinyatakan dalam bentuk persamaan dimana nilai dari satu variabel yang diketahui dapat digunakan untuk menduga nilai dari satu variabel lain yang tidak diketahui.

Dalam penelitian ini terdapat variabel bebas $(\mathrm{X})$ yaitu analisis cost volume profit dan satu variabel terikat (Y) yaitu perencanaan laba dimana variabel bebas (X) yaitu analisis cost volume profit mempunyai hubungan secara positif maupun negatif terhadap variabel terikat (Y) yaitu perencanaan laba. Untuk lebih jelasnya dapat dilihat gambar dibawah ini :

Gambar 2

Model Penelitian

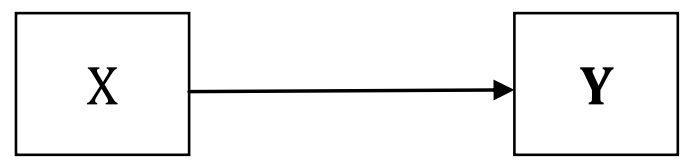

Keterangan :

$\mathrm{X}$ : Variabel Bebas ( Analisis Cost Volume Profit )

$\mathrm{Y}$ : Variabel Terikat ( Perencanaan Laba )

Apabila variabel bebas $(\mathrm{X})$ yaitu analisis cost volume profitnya mempunyai hubungan positif lebih besar daripada variabel terikat (Y) yaitu perencanaan laba maka variabel terikat (Y) yaitu perencanaan labanya akan bertambah, Sebaliknya apabila variabel bebas (X) yaitu analisis cost volume profitnya mempunyai hubungan negatif lebih rendah daripada variabel terikat $(\mathrm{Y})$ yaitu perencanaan laba maka variabel terikat $(\mathrm{Y})$ yaitu perencanaan labanya akan berkurang.

\section{TEKNIK ANALISIS DATA}

Metode atau teknik analisis yang digunakan dalam penelitian ini yaitu :

1. Mengklasifikasikan semua biaya-biaya yang dikeluarkan ke dalam biaya variabel (variable cost) dan biaya tetap (fixed cost).

2. Metode analisis kuadrat terkecil untuk memisahkan biaya semivariabel menjadi biaya tetap dan biaya variabel. Metode ini mengestimasi suatu hubungan linier didasarkan pada persamaan :

$$
\begin{aligned}
& \mathrm{Y}=\mathrm{a}+\mathrm{bx} \\
& \mathrm{b}=\frac{\mathrm{n}\left(\sum \mathrm{XY}-\left(\sum \mathrm{X}\right)\left(\sum \mathrm{Y}\right)\right)}{\mathrm{n}\left(\sum \mathrm{X}^{2}\right)-\left(\sum \mathrm{X}\right)} \\
& \mathrm{a}=\frac{\left(\sum \mathrm{Y}\right)-\mathrm{b}\left(\sum \mathrm{Y}\right)}{\mathrm{n}} \\
& \text { dimana }: \\
& \mathrm{X}=\text { Tingkat aktivitas (variable independent) } \\
& \mathrm{Y}=\text { Total biaya semi variabel (variable dependent) } \\
& \mathrm{a}=\text { Total biaya tetap } \\
& \mathrm{b}=\text { Biaya variabel per unit aktivitas }
\end{aligned}
$$

dimana :

a $=$ Total biaya tetap 


$$
\begin{array}{ll}
\mathrm{n} & =\text { Jumlah observasi } \\
\Sigma & =\text { Jumlah total observasi }
\end{array}
$$

3. Analisis titik impas (Break Event Point/BEP), untuk mendapat suatu keadaan dimana perusahaan tidak memperoleh keuntungan dan tidak mengalami kerugian baik dalam jumlah produk (kuantitas) maupun dalam rupiah.

Di mana:

$$
\begin{aligned}
& \operatorname{BEP}(\text { Rupiah })=\frac{F C}{1-\frac{V C}{S}} \\
& \operatorname{BEP}(\text { unit })=\frac{F C}{P-V C}
\end{aligned}
$$

FC : Fixed Cost (biaya tetap)

VC : Variable Cost (biaya variabel per unit)

$\mathrm{S}$ : Volume Penjualan

$P \quad$ : Harga Jual per unit

Berdasarkan data yang telah diperoleh, analisis titik impas untuk tahun 2009, 2010, dan 2011 dapat dilihat sebagai berikut.

\section{HASIL DAN PEMBAHASAN}

\begin{tabular}{|c|c|c|c|c|c|c|c|c|c|c|}
\hline & \multicolumn{2}{|l|}{ Kamar } & \multicolumn{2}{|c|}{ Restoran } & \multicolumn{2}{|c|}{ Meeting Room } & \multicolumn{2}{|c|}{ Penjualan Laundry } & \multicolumn{2}{|l|}{ Total } \\
\hline & Jumlah & $\%$ & Jumlah & $\%$ & Jumlah & $\%$ & Jumlah & $\%$ & Jumlah & $\%$ \\
\hline Penjualan & 519.035 .000 & $\begin{array}{c}100 \\
\%\end{array}$ & 5.314 .500 & $\begin{array}{c}100 \\
\%\end{array}$ & 11.750 .000 & $\begin{array}{c}100 \\
\%\end{array}$ & 6.745 .000 & $\begin{array}{c}100 \\
\%\end{array}$ & 542.844 .500 & $\begin{array}{c}100 \\
\%\end{array}$ \\
\hline $\begin{array}{l}\text { Dikurangi } \\
\text { beban } \\
\text { variabel }\end{array}$ & 31.434 .680 & $6 \%$ & 4.811 .811 & $91 \%$ & 60.548 & $1 \%$ & 6.456 .347 & $96 \%$ & 42.763 .386 & $8 \%$ \\
\hline $\begin{array}{l}\text { Margin } \\
\text { Kontribusi }\end{array}$ & 487.600 .320 & $94 \%$ & 502.689 & $9 \%$ & 11.689 .452 & $99 \%$ & 288.653 & $4 \%$ & 500.081 .114 & $92 \%$ \\
\hline $\begin{array}{l}\text { Dikurangi } \\
\text { beban tetap }\end{array}$ & & & & & & & & & 77.059 .614 & \\
\hline Laba bersih & & & & & & & & & 423.021 .500 & \\
\hline
\end{tabular}

\section{Tabel 1}

Hotel Tlogo Mas Sarangan : Laporan Laba Rugi Kontribusi Tahun 2009 (dalam Rupiah)

Beban Tetap

77.059 .614

Perhitungan ttitik impas $=$ 83.760 .450

$$
\text { Ratio CM keseluruhan } \quad 0,92
$$

Dari hasil perhitungan di atas, dapat diketahui BEP dalam rupiah sebesar Rp 83.760.450, yang berarti bahwa pada tahun 2009, perusahaan mampu menutupi seluruh biaya tersebut untuk mencapai impas. 
Tabel 2

Hotel Tlogo Mas Sarangan : Laporan Laba Rugi Kontribusi Tahun 2010 (dalam Rupiah)

\begin{tabular}{|c|c|c|c|c|c|c|c|c|c|c|}
\hline & \multicolumn{2}{|c|}{ Kamar } & \multicolumn{2}{|c|}{ Restoran } & \multicolumn{2}{|c|}{ Meeting Room } & \multicolumn{2}{|c|}{$\begin{array}{l}\text { Penjualan } \\
\text { Laundry }\end{array}$} & \multicolumn{2}{|l|}{ Total } \\
\hline & Jumlah & $\%$ & Jumlah & $\%$ & Jumlah & $\%$ & Jumlah & $\%$ & Jumlah & $\%$ \\
\hline Penjualan & $\begin{array}{r}563.463 .00 \\
0\end{array}$ & $\begin{array}{c}100 \\
\%\end{array}$ & 7.420 .500 & $\begin{array}{c}100 \\
\%\end{array}$ & 17.600 .000 & $\begin{array}{c}100 \\
\%\end{array}$ & $\begin{array}{r}8.040 .00 \\
0\end{array}$ & $\begin{array}{c}100 \\
\%\end{array}$ & 596.523 .500 & $\begin{array}{c}100 \\
\%\end{array}$ \\
\hline $\begin{array}{l}\text { Dikurangi beban } \\
\text { variabel }\end{array}$ & 34.203 .963 & $6 \%$ & 6.597 .377 & $89 \%$ & 15.703 & $1 \%$ & $\begin{array}{r}7.562 .37 \\
7\end{array}$ & $94 \%$ & 48.379 .420 & $8 \%$ \\
\hline $\begin{array}{l}\text { Margin } \\
\text { Kontribusi }\end{array}$ & $\begin{array}{r}529.259 .03 \\
7\end{array}$ & $94 \%$ & 823.123 & $11 \%$ & 17.584 .297 & $99 \%$ & 477.623 & $6 \%$ & 548.144 .080 & $92 \%$ \\
\hline Dikurangi beban & & & & & & & & & 94.314 .755 & \\
\hline
\end{tabular}

Beban Tetap

Perumusan titik impas = 102.516.038
94.314.755

----------------------------- = -------------------- $\quad=\mathrm{Rp}$

Dari hasil perhitungan di atas, dapat diketahui BEP dalam rupiah sebesar Rp 102.516.038, yang berarti bahwa pada tahun 2010, perusahaan mampu menutupi seluruh biaya tersebut untuk mencapai impas.

Tabel 3

Hotel Tlogo Mas Sarangan : Laporan Laba Rugi Kontribusi Tahun 2011 (dalam Rupiah)

\begin{tabular}{|c|c|c|c|c|c|c|c|c|c|c|}
\hline & \multicolumn{2}{|c|}{ Kamar } & \multicolumn{2}{|c|}{ Restoran } & \multicolumn{2}{|c|}{ Meeting Room } & \multicolumn{2}{|c|}{$\begin{array}{c}\text { Penjualan } \\
\text { Laundry }\end{array}$} & \multicolumn{2}{|c|}{ Total } \\
\hline & Jumlah & $\%$ & Jumlah & $\%$ & Jumlah & $\%$ & Jumlah & $\%$ & Jumlah & $\%$ \\
\hline Penjualan & 553.151 .400 & $100 \%$ & $\begin{array}{r}11.075 .50 \\
0\end{array}$ & $100 \%$ & $\begin{array}{r}17.800 .0 \\
00\end{array}$ & $100 \%$ & 7.650 .000 & $100 \%$ & $\begin{array}{r}589.676 .9 \\
00\end{array}$ & $100 \%$ \\
\hline $\begin{array}{l}\text { Dikurangi } \\
\text { beban variabel }\end{array}$ & 43.814 .924 & $8 \%$ & 9.911 .738 & $89 \%$ & 45.198 & $1 \%$ & 6.961 .738 & $91 \%$ & $\begin{array}{r}60.733 .59 \\
8\end{array}$ & $10 \%$ \\
\hline $\begin{array}{l}\text { Margin } \\
\text { Kontribusi }\end{array}$ & 509.336 .476 & $92 \%$ & 1.163 .762 & $11 \%$ & 17.754.8 & $99 \%$ & 688.262 & $9 \%$ & $\begin{array}{r}528.943 .3 \\
\end{array}$ & $90 \%$ \\
\hline $\begin{array}{l}\text { Kontribusi } \\
\text { Dikurangi }\end{array}$ & & & & & 02 & & & & 103.076 .1 & \\
\hline beban tetap & & & & & & & & & 02 & \\
\hline Laba bersih & & & & & & & & & $\begin{array}{r}425.867 .2 \\
00\end{array}$ & \\
\hline
\end{tabular}

$$
\begin{aligned}
& \text { Beban Tetap } \quad 103.076 .102 \\
& \text { Perumusan titik impas }= \\
& =\operatorname{Rp} 114.529 .002 \\
& \text { Ratio CM Keseluruhan } \\
& 0,92
\end{aligned}
$$

Dari hasil perhitungan di atas, dapat diketahui BEP dalam rupiah sebesar Rp 114.529.002, yang berarti bahwa pada tahun 2011, perusahaan mampu menutupi seluruh biaya tersebut untuk mencapai impas. 


\section{Analisis Perencanaan Laba}

Analisis perencanaan laba adalah analisis yang memperlihatkan besarnya volume dari laba yang diinginkan.

$$
\text { Penjualan pada laba yang direncanakan }=\frac{\mathrm{FC}+\text { laba }}{1-\frac{\mathrm{VC}}{\mathrm{S}}}
$$

Tabel 4. Hotel Tlogo Sarangan : Perbandingan antara Laba yang direncanakan dengan laba yang terealisasi

Tahun 2009:

Laba yang direncanakan $=15 \%$ X 542.844.500 $=\mathrm{Rp} 81.426 .675$

Laba yang terealisasi $\quad=\operatorname{Rp} 423.021 .300$

Tahun 2010

Laba yang direncanakan $=15 \%$ X 596.523.500 $=\mathrm{Rp} 89.478 .525$

Laba yang terealisasi $\quad=\mathrm{Rp} 453.629 .325$

Tahun 2011 :

Laba yang direncanakan $=10 \%$ X 589.676.900 = Rp 58.967.690

Laba yang terealisasi $=\operatorname{Rp} 425.867 .20$

Dari hasil perhitungan di atas, kita dapat melihat bahwa Hotel Tlogo Mas Sarangan mengalami fluktuasi kenaikan laba tiap tahunnya mulai dari tahun 2009 hingga 2011. Laba tahun 2009 sebesar Rp 423.021.500. Laba tahun 2010 meningkat sebesar Rp 30.807.825 sehingga menjadi Rp 453.829.325. Laba tahun 2011 menurun sebesar Rp 27.962.125 sehingga menjadi Rp 425.867.200.

Hotel Tlogo Mas Sarangan telah menetapkan besarnya perencanaan laba untuk tahun 2009 dan 2010 sebesar 15\% dari total penjualannya; dan untuk tahun 2011, Hotel Tlogo Mas Sarangan menetapkan sebesar 10\% dari total penjualan. Perbedaan ini disebabkan karena adanya renovasi gedung hotel selama tahun 2011 yang menyebabkan kurangnya jumlah pengunjung yang datang

\section{Margin of Safety (Tingkat Keamanan)}

Margin of safety merupakan batas keamanan bagi perusahaan dalam hal terjadi penurunan penjualan, berapa pun penurunan penjualan yang terjadi sepanjang dalam batas-batas tersebut perusahaan tidak akan menderita rugi.

Margin of Safety (Tingkat Keamanan) pada Hotel Tlogo Mas Sarangan berdasarkan data-data yang telah diperoleh, yaitu sebagai berikut:

a. Tahun 2009

$$
\begin{aligned}
& \operatorname{MOS}_{(\mathrm{Rp})}=\text { Total Penjualan }- \text { Penjualan Impas } \\
& =\operatorname{Rp} 542.844 .500-\operatorname{Rp} 83.760 .450 \\
& =\operatorname{Rp} 459.084 .050 \\
& \text { Margin of Savety } \\
& \operatorname{MOS}(\%)=\text { Total Penjualan }
\end{aligned}
$$




$$
\begin{aligned}
& =\frac{459.084 .050}{542.844 .500} \times 100 \% \\
& =85 \%
\end{aligned}
$$

Dari hasil perhitungan di atas diperoleh tingkat margin of safety sebesar $85 \%$ yang berarti bahwa pada tingkat penjualan dan struktur biaya yang ada, jumlah maksimum penurunan target pendapatan penjualan yang tidak menyebabkan perusahaan mengalami kerugian adalah $\mathrm{Rp}$ 459.084.050.

b. Tahun 2010

$$
\begin{aligned}
\operatorname{MOS}_{(\mathrm{Rp})} & =\text { Total Penjualan }- \text { Penjualan Impas } \\
& =\operatorname{Rp} 596.523 .500-\mathrm{Rp} 102.516 .038 \\
& =\operatorname{Rp} 494.007 .462
\end{aligned}
$$
Margin of Savety
$\operatorname{MOS}(\%)=\frac{\text { Total Penjualan }}{\text { T }} \times 100 \%$

$$
\begin{aligned}
& =\frac{494.007 .462}{596.523 .500} \times 100 \% \\
& =83 \%
\end{aligned}
$$

c. Tahun 2011

$$
\begin{aligned}
& \operatorname{MOS}_{(\mathrm{Rp})}=\text { Total Penjualan }- \text { Penjualan Impas } \\
& =\operatorname{Rp} 589.676 .900-\operatorname{Rp} 114.529 .002 \\
& =\operatorname{Rp} 475.147 .898 \\
& \text { Margin of Savety }
\end{aligned}
$$

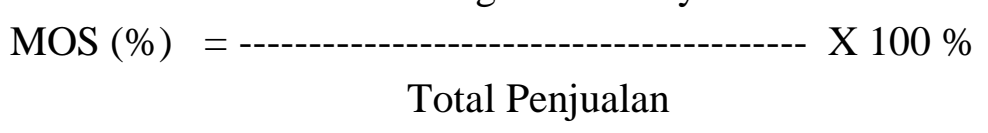

$$
\begin{aligned}
& =\frac{475.147 .898}{589.676 .900} \times 100 \%=81 \%
\end{aligned}
$$

Dari hasil perhitungan MOS tahun 2010 dan 2011 di atas diperoleh tingkat margin of safety mengalami penurunan dari tahun sebelumnya, yaitu dari $85 \%$ menjadi $83 \%$ dan dari $83 \%$ menjadi $81 \%$. Jumlah maksimum penurunan target pendapatan penjualan yang tidak menyebabkan perusahaan mengalami kerugian adalah Rp 494.007.462 (Th 2010) dan Rp 475.147.898 (Tahun 2011) Penurunan yang terjadi tidaklah banyak namun tetap harus diperhatikan.

Semakin tinggi margin of safety suatu perusahaan dikatakan semakin baik karena rentang penurunan penjualan yang dapat ditolerir adalah lebih besar sehingga kemungkinan menderita kerugian rendah. 


\section{KESIMPULAN}

Hasil analisis perencanaan laba, Hotel Tlogo Mas Sarangan menetapkan sebesar $10 \%$ dari total penjualan. Hal ini terlihat dari fluktuasi kenaikan laba yang dialami tiap tahunnya mulai dari tahun 2009 hingga 2011. Laba tahun 2009 sebesar Rp 423.021.500. Laba tahun 2010 meningkat sebesar Rp 30.807.825 sehingga menjadi Rp 453.829.325. Laba tahun 2011 menurun sebesar Rp 27.962.125 sehingga menjadi Rp 425.867.200. Perbedaan ini disebabkan karena adanya renovasi gedung hotel selama tahun 2011 yang menyebabkan kurangnya jumlah pengunjung yang datang.

Hasil perhitungan Margin of safety tahun 2010 dan 2011, mengalami penurunan dari tahun sebelumnya, yaitu dari $85 \%$ menjadi $83 \%$ dan dari $83 \%$ menjadi $81 \%$. Semakin tinggi margin of safety suatu perusahaan dikatakan semakin baik karena rentang penurunan penjualan yang dapat ditolerir adalah lebih besar sehingga kemungkinan menderita kerugian rendah.

\section{DAFTAR PUSTAKA}

Ahmad, Kamaruddin,2005, Akuntansi Manajemen: Dasar-Dasar Konsep Biaya dan Pengambilan Keputusan. PT. Raja Granndo Persada, Jakarta

Blocher, Edward J.,dkk. 2009. Manajemen Biaya: Penekanan Strategis. Alih bahasa oleh Tim Penerjemah Penerbit Salemba.. Buku I Edisi 3. Salemba Empat.

Bustami, Bastian, 2008. Akuntansi Biaya : Kajian Teori dan Aplikasi. Graha Ilmu, Yogjakarta

Garrison, Ray H., Noreen, Eric W., Brewer, Peter C. 2006. Akuntansi Manjerial (alih bahasa: A. Totok Budi Santoso). Buku I. Salemba Empat. Jakarta.

Hansen, Don R., Mowen, Maryanne M. 2000. Cost Management: Accounting Control. Salemba Empat. Jakarta.

Hongren, Charles T., Datar, Srikant M., Foster, George. 2005. Akuntansi Biaya: Pendekatan Manajerial (alih bahasa: Desi Adhariani). Edisi Kesebelas. Indeks. Jakarta.

Ikatan Akuntan Indonesia. 2004. Standar Akuntansi Keuangan. Salemba Empat. Jakarta.

Mulyadi. 2000. Akuntansi Biaya. Edisi Kelima. Aditya Media. Yogyakarta.

Polomeni, Ralph S., James A. Cason. 1991. Cost Accounting. McGraw Hill, New York. 